\title{
The Holy Grail of Resource Assessment: Low Cost Ground-Based Measurements with Good Accuracy
}

\section{Introduction}

We developed a procedure to derive solar resource data from PV performance data such as measured by Enphase Energy Inc. microinverters, which have been deployed with millions of PV modules and have been providing reliable data with a 5-minute temporal resolution since 2011 and for some early systems since 2007.

The ac power, $P_{2}$, data are used to back-solve for the unknown direct normal irradiance (DNI) and diffuse horizontal irradiance (DHI). The procedure required the development of two key methods: (1) determining the global tilted irradiance (GTI), otherwise known as the plane-of-array (POA) irradiance, from the $P_{a c}$, and (2) determining the DNI and DHI from the GTI.

\section{Method}

The method to determine the DNI and DHI from the GTI is a modification of the DIRINT model by Perez, which separates input values of GHI into their DNI and DHI components. The modification substitutes GTI for GHI and adds an iterative procedure to adjust the global clearness index to improve the derived values of DNI and DHI. The resulting model is referred to as the GTI-DIRINT model.

The method to determine the GTI from the $P_{\text {an }}$ uses inverted PV performance models and solves a quadratic equation for the GTI from the input variables $P_{a c}$, wind speed, WS, dry bulb temperature, $T_{a}$, and the $P V$ module temperature coefficients. A step was added to the GTI-DIRINT model to correct for the angle-of-incidence (AOI) effects for both beam and diffuse radiation.

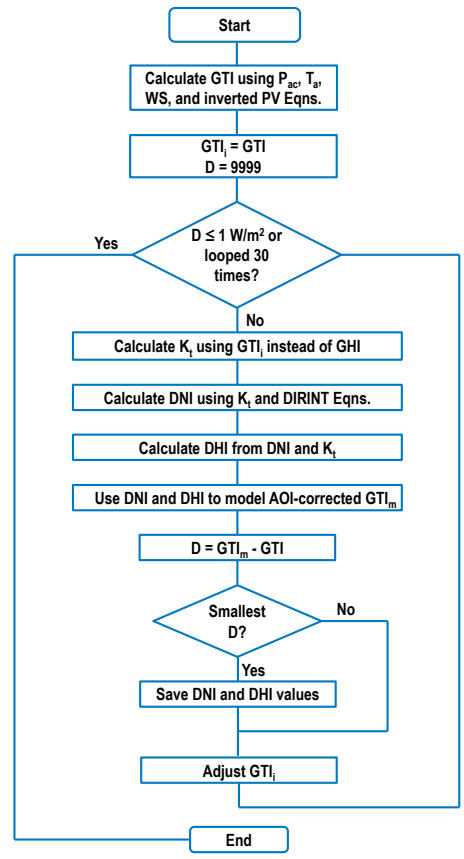

Flow chart for deriving DNI and DHI from $P_{a c}$

\section{Data}

We designed the validation experiment to include five identical PV module/Enphase Energy Inc. micro-inverter systems, each with a different tilt and azimuth orientation. Each of the five systems is instrumented to measure the $P_{a c}$ and GTI for comparison with the modeled values. The existing DNI and DHI measurements from the NREL's Solar Radiation Research Laboratory are also used for comparison with modeled values.

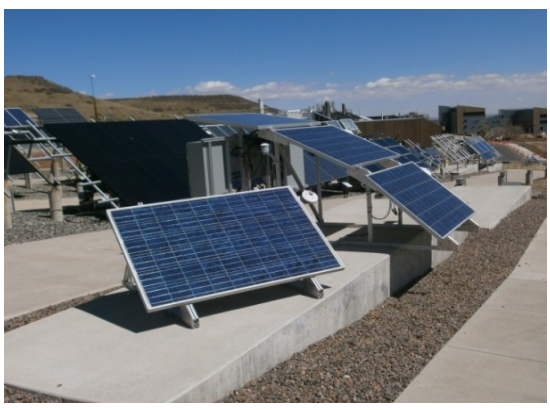

PV modules with micro-inverters installed at NREL. Three PV modules are south-facing, with tilts of PV module (not shown) is installed on a nearby two-axis tracker.

\section{Results}

Using the characteristic data for the PV systems; the Enphase Energy Inc. $P_{a c}$ data; the ASOS $T_{a}$ and WS data; values of DNI and DHI were derived for each of the three south-facing fixed-tilt PV systems. Each set of the derived DNI and DHI values were then used to model the $P_{a c}$ of each of the five PV systems for the purpose of comparing the differences between the modeled and measured values.

For comparison, the tables also include results when the model inputs are measured or DIRINT derived values of DNI and DHI.

Mean Bias Deviation (MBD) and Root-Mean-Square Deviation (RMSD) for DIRINT and GTI-DIRINT Modeled Values of DNI, DHI, and GHI when using Measured GHI with DIRINT and Enphase Measured $P_{x c}$ with GTI-DIRINT for the Various PV Module Tilt and Azimuth Orientations.

\begin{tabular}{|c|c|c|c|c|c|c|}
\hline Model//nput & $\begin{array}{l}\text { DNI } \\
\text { MBD } \\
(\%)\end{array}$ & $\begin{array}{l}\text { RMSD } \\
(\%)\end{array}$ & $\begin{array}{l}\text { DHI } \\
\text { MBD } \\
(\%)\end{array}$ & $\begin{array}{l}\text { RMSD } \\
(\%)\end{array}$ & $\begin{array}{l}\text { GHI } \\
\text { MBD } \\
(\%)\end{array}$ & $\begin{array}{l}\text { RMSD } \\
\text { (\%) }\end{array}$ \\
\hline $\begin{array}{l}\text { DIRINT/GHI } \\
\text { GTI-DIRINT/ }\end{array}$ & 2.0 & 19.2 & -5.1 & 35.1 & $\cdots$ & $\cdots$ \\
\hline$P_{a c}(10,180)$ & 2.2 & 26.8 & -3.9 & 38.0 & 1.2 & 10.6 \\
\hline$P_{\text {ac }}(25,180)$ & 1.9 & 27.1 & -3.6 & 38.1 & 0.9 & 10.9 \\
\hline
\end{tabular}

Mean Bias Deviation (MBD) and Root-Mean-Square Deviation (RMSD) for Modeling the $P_{\mathrm{ac}}$ for the Different PV Module Orientations when using the Measured DNI and DHI; the DIRINT Modeled DNI and DHI Derived from the Measured GHI; and the GTI-DIRINT Modeled DNI and DHI Derived from the Enphase Measured P for the Various PV Module Tilt and Azimuth Orientations.

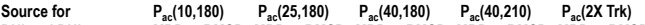
DNI and DHI MBD RMSD MBD RMSD MBD RMSD MBD RMSD MBD RMSD \begin{tabular}{lllllllllll} 
& $(\%)$ & $(\%)$ & $(\%)$ & $(\%)$ & $(\%)$ & $(\%)$ & $(\%)$ & $(\%)$ & $(\%)$ & $(\%)$ \\
\hline Measured & -0.4 & 7.9 & 0.3 & 7.9 & 1.4 & 8.5 & 2.3 & 9.5 & 2.3 & 8.3
\end{tabular} $\begin{array}{llllllllrrr}\text { Measured } & -0.4 & 7.9 & 0.3 & 7.9 & 1.4 & 8.5 & 2.3 & 9.5 & 2.3 & 8.3 \\ \text { DIRINT/GHI } & -0.3 & 7.9 & 0.5 & 8.2 & 1.7 & 9.3 & 2.4 & 10.5 & 2.8 & 11.5\end{array}$ GTI-DIRINT/ \begin{tabular}{lllllllllll}
$\mathrm{P}_{\mathrm{ac}}(10,180)$ & 1.1 & 7.4 & 1.9 & 8.3 & 3.1 & 9.5 & 3.9 & 11.0 & 3.3 & 16.5 \\
\hline & 0.7 & 8.1 & 1.5 & 7.6 & 2.7 & 8.4 & 3.4 & 10. & 3.3 & 17.1
\end{tabular} \begin{tabular}{lllllllllll}
$\mathrm{P}_{\mathrm{ac}}(25,180)$ & 0.7 & 8.1 & 1.5 & 7.6 & 2.7 & 8.4 & 3.4 & 10.2 & 3.3 & 17.1 \\
$\mathrm{P}_{\mathrm{N}}(40,180)$ & -0.1 & 8.8 & 0.6 & 7.8 & 1.8 & 7.9 & 2.5 & 9.9 & 3.1 & 18.1 \\
\hline
\end{tabular}

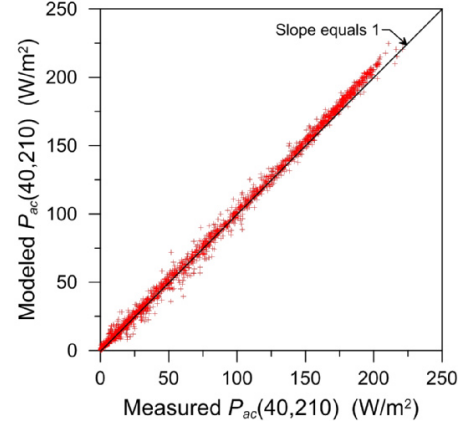

measured $P_{a c}(25,180)$

\section{Uncertainty Analysis}

The uncertainty of the method for predicting the annual $P_{a c}$ was determined and quantified by the source element of the uncertainty. The uncertainty of the method was also compared with other modeling methods using measured $\mathrm{GHI}$ and satellite derived $\mathrm{GHI}$ as the sources of the irradiance data.

Uncertainty Elements for Modeling the Annual $P_{a c}$ by the Various Methods.

\begin{tabular}{|c|c|c|c|}
\hline \multirow[t]{2}{*}{ 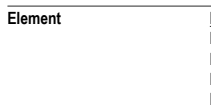 } & \multicolumn{3}{|c|}{ Method for Modeling the Pac } \\
\hline & $\begin{array}{l}\text { Measured GHI, } \\
\text { DIRINT Model, } \\
\text { Perez Tilt Model } \\
\text { Bias Limit ( } \% \%)\end{array}$ & $\begin{array}{l}\text { Satellite GHI, } \\
\text { DIRINT Model, } \\
\text { Perez Tilt Model } \\
\text { Bias Limit }( \pm \%)\end{array}$ & $\begin{array}{l}\text { Enphase Measured } P_{a c} \\
\text { GTI-DIRINT Model, } \\
\text { Perez Tilt Model } \\
\text { Bias Limit }( \pm \%)\end{array}$ \\
\hline GHI & 2.0 & 5.0 & .... \\
\hline Enphase measured $P_{a c}$ & $\ldots . .$. & $\ldots$ & 2.5 \\
\hline PV power rating & 3.0 & 3.0 & $4.2^{*}$ \\
\hline PV module binning & 1.0 & 1.0 & $1.4^{*}$ \\
\hline DIRINT + Perez Tilt Model & 1.5 & 1.5 & $\ldots$ \\
\hline GTI-DIRINT + Perez Tilt Model & $\ldots$ & .... & 1.5 \\
\hline Spectral effect & 1.8 & 1.8 & 0.5 \\
\hline Irradiance effect & 1.0 & 1.0 & $1.4^{*}$ \\
\hline AOl effect & 0.5 & 0.5 & $0.7^{*}$ \\
\hline \multicolumn{4}{|l|}{ Temperature effects } \\
\hline$y$ bias limit of $\pm 7.5 \%$ & 0.8 & 0.8 & $1.1^{*}$ \\
\hline ASOS location & 1.0 & 1.0 & $1.4^{*}$ \\
\hline Temperature model & 1.2 & 1.2 & $1.7^{*}$ \\
\hline Inverter model & 1.0 & 1.0 & $1.4^{*}$ \\
\hline Inverter clipping & $\ldots$ & $\ldots$ & 1.0 \\
\hline Soiling estimate & 2.0 & 2.0 & 0.5 \\
\hline Root-sum-square of bias limits & 5.4 & 7.1 & 6.3 \\
\hline
\end{tabular}

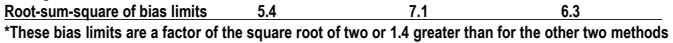
Thecause they are used twice, once when deriving the $\mathrm{DNI}$ and $\mathrm{DH}$ f from the measured $\mathrm{P}_{\mathrm{ac}}$ and again because they are used twice, once when deriving the DNI and DHI from the
when using the derived DNI and DHI to model the $\mathrm{P}_{\text {ac }}$ of another PV system.

\section{Summary}

Using PV performance data from PV modules with micro-inverters affords the opportunity to provide ground-based solar resource values of DNI and DHI critical for developing PV projects. From the measured $P_{a c}$, the DNI and DHI were derived, and then used to model the performance of other PV modules with micro-inverters with different azimuth and tilt orientations. The annual MBDs were within $\pm 4 \%$, and only $1 \%$ greater than when the PV performance was modeled using high quality irradiance measurements. An uncertainty analysis shows the method's uncertainty for modeling the annual ac energy for a PV system to be $\pm 6.3 \%$, which is less than the $\pm 7.1 \%$ uncertainty when modeling the PV performance using satellitebased global horizontal irradiance data. 